\title{
Differences in the management of ruptured intracranial aneurysms: a survey of practice amongst British neurosurgeons
}

\author{
H MARSH, R S MAURICE-WILLIAMS, K W LINDSAY \\ From the Department of Neurosurgery, Royal Free Hospital and School of Medicine, London, UK
}

SUMMARY British consultant neurosurgeons in post for at least one year were sent a postal questionnaire about the way in which they managed patients with ruptured aneurysms; $87 \%$ replied. Wide differences were evident in almost all aspects of treatment, before, during and after surgery. A consensus of opinion appeared in only a few areas: the employment of magnification during surgery, the use of clipping as the preferred method of surgical treatment, and a general reluctance to operate on patients with a depressed conscious level within a week of haemorrhage.

Rupture of an intracranial aneurysm is one of the commonest conditions requiring neurosurgical attention. Despite major advances in treatment over the last few decades, the overall prognosis of patients admitted to neurosurgical care remains unsatisfactory. ${ }^{12}$ Many aspects of treatment are or have been the subject of controversy. Amongst these are the optimum time for surgery, the use of hypotensive and antifibrinolytic drugs to reduce the risk of rebleeding, and whether patients who are elderly or who have non-ruptured aneurysms should be subjected to surgery. Some surgical techniques such as peroperative hypothermia or hypotension and the use of temporary clipping of main arteries during dissection of an aneurysm have not been universally accepted.

Although there has been widespread discussion of these and other questions, personal observation had suggested that there are wide differences of practice amongst British neurosurgeons in the way in which they manage patients with aneurysms. We have attempted to establish the extent of these variations by carrying out a postal survey.

\footnotetext{
Address for reprint requests: RS Maurice-Williams, Department of Neurosurgery, Royal Free Hospital, Pond Street, London NW3 2QG, UK.
}

Received 20 May 1986 and in revised form 28 January 1987. Accepted 30 January 1987

\section{Method}

In April 1984 we sent a postal questionnaire to the 107 consultant neurosurgeons in Great Britain, Northern Ireland, and the Irish Republic who had been in post for at least one year. At this time there were a further eight posts which were vacant or had been filled only recently.

\section{Results}

\section{A: Returns}

Ninety three out of $107(87 \%)$ questionnaires were returned. Three of the respondents said they were answering on behalf of colleagues as well as themselves. These replies have been counted as only a single response each. Some respondents did not answer all the questions and, where this is so, the number of respondents is indicated.

\section{B: Replies to questions}

1. The approximate number of cases of subarachnoid haemorrhage (SAH) admitted per consultant per year (87 replies), shown in table 1.

2. Number of aneurysm operations per consultant per year (87 replies), shown in table 2 .

3. Admission policies for patients with $S A H$.

(a) Age limits (90 replies). Forty nine surgeons had no age limit for accepting a patient with SAH. Forty one would not accept patients above a certain age: 65 years (19 surgeons); between 65 and 70 years depending on condition ( 2 surgeons); 70 years (18 
Table 1 Number of patients with SAH admitted per consultant per year ( 87 replies)

\begin{tabular}{ll}
\hline No of patients & No of Consultants \\
\hline $0-10$ & 0 \\
$11-20$ & 13 \\
$21-30$ & 25 \\
$31-40$ & 27 \\
$41-50$ & 18 \\
$51-60$ & 4 \\
\hline
\end{tabular}

Table 2 Number of aneurysm operations per consultant per year ( 87 replies)

\begin{tabular}{ll}
\hline No of operations & No of Consultants \\
\hline $0-10$ & 2 \\
$11-20$ & 36 \\
$21-30$ & 35 \\
$31-40$ & 14 \\
\hline
\end{tabular}

surgeons); 72 and 80 years ( 1 surgeon each).

(b) Condition of patient. Admission as soon as referred, regardless of clinical condition: 30 surgeons. Good condition patients transferred as soon as referred, poor condition patients transferred only if and when they improved: 54 surgeons. Patients not transferred until several days from haemorrhage, to allow for stabilisation of condition: nine surgeons. Five neurosurgeons only accepted patients after prior evaluation by a neurologist.

4. Preoperative management

(a) Antifibrinolytic treatment: thirty one surgeons used routine antifibrinolytic therapy, 62 did not.

(b) Blood pressure control: seventy four surgeons did not attempt to treat hypertension prior to operation, 16 lowered the blood pressure to normal levels but none sought to lower it to below normal.

(c) Sedation: given routinely by 16 of 93 surgeons.

(d) Strict bed rest: enforced by 77 of 93 surgeons.

(e) Angiography (91 replies). Forty one surgeons obtained angiography as soon as possible after admission and a further two did so in the absence of a neurological deficit. Forty six delayed angiography until the patient was judged fit for surgery. Two only obtained angiography when 7 days had elapsed since the last haemorrhage, two avoided days 4 and 5 after the haemorrhage. Fifty five surgeons had angiography performed under general anaesthesia, 35 had it performed under local anaesthesia.

5. Timing of surgery

(a) Patients in good condition at admission (89 replies): 54 surgeons operated "as soon as possible", 35 operated after waiting for a variable interval from the last haemorrhage, shown in table 3.

(b) Patients with a major focal neurological deficit but intact conscious level (89 replies): 15 operated in first
Table 3 Planned delay from haemorrhage before surgery in good condition patients (35 consultants)

\begin{tabular}{lc}
\hline & No \\
\hline 3- 4 days & 1 \\
$3-7$ days & 3 \\
$5-7$ days & 12 \\
$7-10$ days & 8 \\
10-14 days & 9 \\
Over 14 days & 2 \\
\hline
\end{tabular}

week, 30 operated in second week, 16 operated after second week, 28 operated only after resolution of deficit.

(c) Patients with depressed conscious level but no focal neurological deficit at the time of admission (91 replies): 7 operated in first week, 15 operated in second week, 6 operated after second week, 63 operated only when conscious level had recovered.

(d) Poor condition patients with cerebral compression from haematoma: asked whether they operated acutely on such patients to relieve cerebral compression, 23 replied that they usually operated, 16 never operated, 54 would occasionally operate.

6. Operative technique

(a) Routine use of pre-operative cerebral dehydrating agent: used by 40 surgeons.

(b) Routine drainage of cerebrospinal fluid: used by 44 surgeons ( 25 by ventricular drainage, 19 by lumbar drainage).

(c) Magnification: 89 used magnification (88 used operating microscope, nine used magnifying loupes, depending on the circumstances), four used no magnification at all.

(d) Unruptured aneurysms: 19 surgeons did not operate on unruptured aneurysms. Seventy three would operate on some unruptured aneurysms depending on the circumstances; one did not reply.

(e) Controlled Hypotension during surgery: used by 65 (only 2 routinely used profound hypotension and sought to lower the systolic blood pressure below 60 $\mathrm{mm} \mathrm{Hg}$ ). Not used by 28 .

(f) Hypothermia: never used by 84 surgeons; sometimes used by nine surgeons, of whom only one employed deep hypothermia with cardiac bypass.

(g) Temporary clipping of main artery to facilitate dissection of an aneurysm which has not bled at operation (89 replies): often used by five surgeons; sometimes used by 43 surgeons; never used by 41 surgeons.

(h) Preferred method of treating aneurysms: clipping, 84; clipping and wrapping, 9; wrapping alone, 0 .

(i) Proximal "indirect" operations:

(a) Common carotid artery ligation: never used, 37; used less than five times a year, 56; used more than five times a year, 0 .

(b) Clipping of the proximal anterior cerebral artery for anterior communicating aneurysms: never used, 71; 
occasionally used, 22 ; routinely used, 0 .

7. Post operative management

(a) Anticonvulsants: used routinely, 47; not used routinely, 46.

(b) High dose steroids: used routinely, 44; not used routinely, 49.

(c) Treatment of post operative ischaemia: 18 surgeons used a routine prophylactic regime; 75 surgeons did not.

If symptoms of cerebral ischaemia appear after surgery the following agents were used:

Plasma expanders (66 surgeons); drugs to induce hypertension (46); steroids (30); dehydrating agents (23).

(d) Post operative check angiography: obtained routinely by 17 surgeons.

\section{Discussion}

There have been few published surveys of differences in surgical practice in the British Isles, and, so far as we are aware, none has concerned neurosurgery with the possible exception of Le Vay's questionnaire on the management of lumbar disc protrusions which was circulated to both neurosurgeons and orthopaedic surgeons. ${ }^{3}$ Although subject to the limitations and simplifications which a postal questionnaire always involves, our survey has revealed major differences in the way in which British neurosurgeons manage patients with ruptured intracranial aneurysms.

The neurosurgeon's management begins as soon as a patient is referred to him. The admission policy he adopts will exert a considerable influence on the outcome figures for his unit. Any selection of patients and any delays in transfer to neurosurgical care will prevent patients with an unfavourable prognosis from entering the population he treats. A recent study has shown the way in which different admission policies approximating to those in general use can bias both surgical and management results by altering the structure of the population of patients entering neurosurgical care. ${ }^{4}$ An "open door" policy of transferring all patients as soon as they are referred, regardless of clinical condition, will produce the least favourable results, for it will lead to the surgeon having to treat many patients who are either in a very poor condition or who are about to deteriorate. Our survey has revealed that admissions policies do indeed vary and that fewer than one third of British neurosurgeons operate an open door policy. This means that it may seldom be possible to make valid comparisons between the results of treatment at different centres.

Our respondents could not agree on a maximum age for treating patients with subarachnoid hae- morrhage (SAH). This reflects a rather surprising lack of firm evidence as to whether the results of aneurysm surgery are related to the patient's age. Thus while some series have found that surgical mortality increases steadily with age, ${ }^{56}$ Nornes and Wikeby found that surgical mortality was lower in the 7 th decade than in the $4 \mathrm{th}^{7}$ and Sengupta and colleagues reported good results in patients between the ages of 60 and $71 .^{8}$ It is difficult to reconcile such disparaties but, as Martindale and Garfield have pointed out, older patients subjected to aneurysm surgery tend to be highly selected, a relatively small number chosen from amongst a large number of elderly patients with SAH. ${ }^{9}$ In addition, it can be difficult to disentangle the influence of age alone on the outcome, for older patients are more likely to have hypertension or other serious intercurrent diseases than younger patients with SAH.

We asked each surgeon to state the number of patients with SAH he admitted per year, and the number of aneurysm operations he performed. Their replies revealed a relatively small scatter of experience, the great majority of surgeons carrying out between 15 and 35 operations per year. This is as one would expect, for so far there has been little tendency for British neurosurgeons to develop as specialist aneurysm surgeons. The replies allow one to make an estimate of the proportion of patients with SAH who reach neurosurgical care. If the incidence of SAH is taken as being 12 per 100,000 per year, an estimate which probably errs on the low $\operatorname{side}^{10}$ then the expected number of cases per year in the British Isles is about $6,5000-7,000$. The figures returned by our respondents suggest that perhaps 3,000 to 3,500 patients are treated by neurosurgeons each year. Even allowing for the fact that $15 \%$ of patients die before reaching hospital or shortly afterwards ${ }^{11-13}$ and that many of our respondents may have given approximate estimates it would appear that a substantial proportion (possibly as many as half) of the patients with SAH who reach hospital in Britain do not reach neurosurgical care.

Prior to operation there would appear to be no standard approach to management. At this stage the main threats to the patient are rebleeding and delayed cerebral ischaemia. These present the surgeon with a dilemma for measures which may reduce the likelihood of rebleeding such as hypotensive therapy and antifibrinolytic treatment may increase the risk of ischaemia. On the other hand treatment to counteract cerebral ischaemia, such as raising the blood pressure and expanding the blood volume, may precipitate recurrent haemorrhage.

A number of general measures are employed to minimise fluctuations in blood pressure and hence reduce the risk of rebleeding. ${ }^{14}$ Of these the most 
widely used are strict bedrest and sedation. We are aware of no evidence for their efficacy and they are not without some theoretical risks. For example they might increase the risk of thromboembolism and chest infection. Most of our respondents enforced strict bed rest but less than $20 \%$ used routine sedation.

Fewer than $20 \%$ used hypotensive treatment prior to operation and none attempted to lower the blood pressure to below normal levels. Although there have been no major trials of hypotensive treatment used alone there is evidence that hypotension can be hazardous, especially in patients who are drowsy, who have a major neurological deficit or who show fluctuations in their clinical state. ${ }^{1516}$ Furthermore, even patients in a good condition often have reduced cerebral perfusion so that very close clinical monitoring is required if hypotension is used. Blood pressure control is often extremely difficult in the periods soon after a $\mathrm{SAH}^{16}$ and it is much more difficult to lower the blood pressure below normal than to eliminate extremes of hypertension. ${ }^{17}$

The continued use of antifibrinolytic drugs by a substantial minority of British neurosurgeons can only be regarded as surprising. Although a large number of trials have produced conflicting evidence about the efficacy of these agents in reducing rebleeding, ${ }^{18}$ a well designed large scale multi-centre trial which had been published by the time of our survey had finally established that antifibrinolytic treatment has no effect on the overall outcome in patients with SAH, as a reduction in rebleeding is counter-balanced by an increase in cerebral ischaemia. ${ }^{19}$

The optimum timing of surgery and hence of preoperation angiography remains a major subject of controversy and the disparate practises revealed by our survey suggest some degree of confusion amongst British neurosurgeons. In general, early surgery is technically difficult and is attended by poor results while if operation is postponed for 14 days or more from the time of the last haemorrhage a very low surgical mortality can be attained..$^{20-22}$ Of course, delayed surgery means that many patients will deteriorate and die from rebleeding and other causes during the waiting period, so that the good surgical results may disguise poor management results. At the present time it is uncertain whether early or delayed surgery produces the best overall results. ${ }^{20}$ However, there is some evidence that results are particularly poor if surgery is carried out during the second half of the first week after haemorrhage when cerebral vasospasm and delayed cerebral ischaemia are beginning to develop ${ }^{2324}$ and recently there has been a move towards very early surgery, within the first 48 to 72 hours. Some good results have been reported ${ }^{1325}$ and it has been suggested that surgery at this stage may not only prevent rebleeding but also permit effective prophyllaxis against delayed cerebral ischaemia by the removal of clot from the basal systems at the time of surgery and by allowing treatment with hypertension and blood volume expansion once the aneurysm has been excluded from the circulation. ${ }^{2025}$

The patient with acute cerebral compression caused by an intracerebral haemorrhage from an aneurysm presents a special case for emergency surgery. Such patients are usually in a poor clinical condition and although a very good result is sometimes obtained, the overall operative mortality is high, ranging from $50 \%$ to $80 \%$ with many survivors left severely disabled. ${ }^{26}{ }^{27}$ The case for emergency surgery in these patients remains unproven and the lack of consensus amongst our respondents reflects this.

The greatest change in the purely technical side of aneurysm surgery in the last 20 years or so has been the introduction of the operating microscope. Few neurosurgeons can doubt that this had led to greatly improved surgical results although this has not been established by any incontrovertible evidence. Younger neurosurgeons find it difficult to understand how their elders were able to clip aneurysms without the controlled magnification, intense illumination and binocular vision at depth provided by the microscope. What is surprising is not that $95 \%$ of our respondents used the microscope but that four surgeons used no magnification at all!

All our respondents preferred to clip aneurysms if possible. A few combined clipping with investment of the sac, but none employed wrapping alone. Although wrapping has been described as an alternative method of dealing with aneurysms ${ }^{28} 29$ it has two disadvantages compared with clipping: it requires total exposure of the aneurysm sac (with a greater risk of per-operative rupture) and even if the surgeon achieves a complete investment of the aneurysm, the sac is still not excluded from the circulation and may rebleed in the future.

Judging by the results of our survey, the "indirect" operations of carotid ligation (for internal carotid artery aneurysms) and occlusion of the larger proximal anterior cerebral artery (for anterior communicating artery aneurysms) which were so widely used in the 1950s and 1960s are no longer employed except for occasional patients and many British neurosurgeons no longer perform these operations at all. These procedures do not exclude aneurysms from the circulation and hence cannot totally abolish the risk of rebleeding, though they may lessen it. Their abandonment probably indicates the improvement in the surgeons' ability to clip aneurysms which has resulted from the introduction of the microscope.

Our survey revealed no uniformity in the use of

(2)


various adjuncts to surgery. It seemed surprising that most surgeons did not routinely use dehydrating agents or drainage of cerebrospinal fluid to facilitate brain retraction, for these manoeuvres are not believed to be associated with any dangers, apart from the very small risk of rupture of the aneurysm if administration of a dehydrating agent and release of cerebrospinal fluid are carried out simultaneously. ${ }^{30}$ Most neurosurgeons used hypotension during dissection of the sac, though only two routinely lowered the blood pressure to less than $60 \mathrm{~mm} \mathrm{Hg}$. On the other hand most neurosurgeons were reluctant to apply temporary clips to a main artery while the aneurysm was being dissected. Both procedures are designed to minimise the risk of per-operative rupture of the aneurysm, but both may increase the risk of cerebral ischaemia. There is evidence that extremes of hypotension are relatively safe, especially if combined with simultaneous blood volume expansion, ${ }^{31}$ but the same is not true of temporary clipping which may damage the wall of the artery concerned as well as interrupting the flow of blood within it.

Hypothermia was widely employed 20 to 30 years ago but has now largely been abandoned. Moderate hypothermia (to approximately $30^{\circ} \mathrm{C}$ ) was a cumbersome procedure which was shown to confer no overall benefit. ${ }^{32}$ Deep hypothermia (to 15 to $20^{\circ} \mathrm{C}$ ) using cardiopulmonary bypass permits total circulatory arrest for up to $\mathbf{4 5}$ minutes. It may enable the dissection and occlusion of otherwise inoperable aneurysms but when first introduced it was associated with serious problems from inability to reverse fully the anticoagulation required for the bypass machine. ${ }^{33}$ Recently, improved understanding of the physiology of clotting has partly solved this problem and deep hypothermia has been tried again with improved results. ${ }^{34}$ Nevertheless, only one British neurosurgeon is currently using this technique.

The survey results indicate a lack of any standard approach to post-operative management. There is no evidence for the value of high dosage steroids after aneurysm surgery, but it is known that up to $30 \%$ of operations on supratentorial aneurysms are followed by fits at some time, the incidence varying with the site of the aneurysm, ${ }^{35}$ and it does seem curious that half our respondents did not use routine anticonvulsants, for seizures, especially in the immediate post-operative period can give rise to a number of problems. To take but one example a post-operative fit may lead to obstruction of the airway and increase the risk of ischaemia for a brain whose circulation may be in a precarious state.

Cerebral ischaemia is the principal post-operative complication of aneurysm surgery yet the majority of our respondents did not use any prophylactic regime to counter this danger, even though both hyper- tension and blood volume expansion may lessen the danger of this complication without any great risk once the aneurysm has been clipped. ${ }^{36} 37$

Only a minority of our respondents used routine check angiography after aneurysm surgery, although series published by experienced surgeons have established that check angiography will reveal that some aneurysms thought to have been occluded successfully are only clipped partially, if at all. ${ }^{38} 39$

To the non-neurosurgeon these many variations in the management of a common disorder may seem surprising. To some extent this may be due to a reluctance on the part of a generally conservative group of surgeons to abandon certain well established modes of treatment. However, it has to be said that there is simply no firm evidence for or against most forms of treatment with the possible exception of antifibrinolytic therapy. It is clear that many other aspects of the treatment of patients with SAH deserve definitive and controlled investigation in the hope that the delineation of a rational scheme of management will help to reduce the mortality and morbidity of this very grave condition.

We thank the large number of neurosurgeons who made this survey possible by completing and returning the questionnaire.

\section{References}

1 Adams HP, Kassell NF, Torner JC, et al. Early management of aneurysmal subarachnoid haemorrhage. A report of the Cooperative Aneurysm Study. J Neurosurg 1981;54:141-5.

2 Ropper AM, Zervas NT. Outcome 1 year after SAH from cerebral aneurysm. J Neurosurg 1984;60:909-15.

3 Le Vay D. A survey of surgical management of lumbar disc prolapse in the United Kingdom and Eire. Lancet 1967;1:1211-3.

4 Maurice-Williams RS, Marsh $H$. Ruptured intracranial aneurysms: the overall effect of treatment and the influence of patient selection and data presentation on the reported outcome. J Neurol Neurosurg Psychiatry 1985;48:1208-12.

5 Fortuny LAI, Prieto-Valiente L. Long-term prognosis in surgically treated intracranial aneurysm. Pt. 1: mortality. J Neurosurg 1981;54:26-34.

6 Suzuki J, Onuma T, Yoshimoto T. Results of early operation on cerebral aneurysm. Surg Neurol 1974;11:407-12.

7 Nornes H, Wikeby P. Results of microsurgical management of intracranial aneurysms. $J$ Neurosurg 1979;51:608-14.

8 Sengupta RP, Lassman LP, Hankinson J. Scope of surgery for intracranial aneurysms in the elderly: a preliminary report. Brit Med J 1978;2:246-7.

9 Martindale BV, Garfield J. Subarachnoid haemorrhage above the age of 59: are intracranial investigations justified? Brit Med $J$ 1978;1:465-6.

10 Gudmundson C. Primary subarachnoid haemorrhage in Iceland. Stroke 1973;4:764-7.

11 Crawford MD, Sarner M. Ruptured intracranial aneurysmCommunity Study. Lancet 1965;2:1254-7.

12 Phillips LH, Whisnant JP, O'Fallon WM, Sundt TM. The unchanging pattern of subarachnoid haemorrhage in a community. Neurology 1980;30:1034-40.

13 Ljunggren B, Saveland H, Brandt L, Zygmunt S. Early operation 
and overall outcome in aneurysmal subarachnoid haemorrhage. J Neurosurg 1985;62:547-51.

14 Hopkins LN. The history of subarachnoid haemorrhage: hospital environment and nursing care. In: Hopkins LN, Long DM, eds. Clinical Management of Intracranial Aneurysms. New York: Raven Press, 1982:21-8.

15 Mullan S. The initial medical management of ruptured intracranial aneurysms. In: Morley TP, ed. Current Controversies in Neurosurgery. Philadelphia: Saunders, 1976:259-69.

16 Grand W. Pre-operative blood pressure in the aneurysm patients. In: Hopkins LN, Long DM, eds. Clinical Management of Intracranial Aneurysms. New York: Raven Press, 1982:29-38.

17 Mullan S. Conservative management of the recently ruptured aneurysm. Surg Neurol 1975;3:27-32.

18 Ramirez-Lassepas M. Antifibrinolytic therapy in subarachnoid haemorrhage caused by ruptured intracranial aneurysm. Neurology 1981;31:316-22.

19 Vermeulen M, Lindsay KW, Murrary GD, et al. Antifibrinolytic treatment in subarachnoid haemorrhage. New Engl $J$ Med 1984;311:432-7.

20 Kassell NF, Drake CG. Timing of Aneurysm Surgery. Neurosurgery 1982;10:514-9.

21 Adams CBT, Loach AB, O'Laoire SAO. Intracranial aneurysms - analysis of results of microneurosurgery. Brit Med J 1976;2:607-9.

22 Krayenbuhl H, Yasargil MG, Flamm ES, et al. Microsurgical treatment of intracranial saccular aneurysm. J Neurosurg 1972;37:678-86.

23 Yoshimoto T, Uchida K, Kaneko U, et al. An analysis of follow up results of 1,000 intracranial saccular aneurysms with definitive surgical treatment. J Neurosurg 1979;50:152-7.

24 Sano K, Saito I. Timing and indication of surgery for ruptured intracranial aneurysms with regard to cerebral vasospasm. Acta Neurochir 1978;41:49-60.

25 Mizukami J, Kawese T, Tazawa T. Prevention of vasospasm by early operation with removal of subarachnoid blood. Neurosurgery 1982;10:301-7.

26 Ljunggren B, Brandt L, Kagstrom E, et al. Results of early oper- ations for ruptured aneurysms. J Neurosurg 1981;54:473-9.

27 Graf CJ. Results of direct attack on nonfistulous intracranial aneurysms with remarks on statistics. $J$ Neurosurg 1955;12:146-53.

28 Dutton J. Acrylic investment of intracranial aneurysms. $J$ Neurosurg 1969;31:652-7.

29 Taylor JC, Choudhary AR. Reinforcement with gauze wrapping for ruptured aneurysms of the middle cerebral artery. $J$ Neurosurg 1977; 47:828-32.

30 Rosenorn J, Westergaard L, Hansen PH. Mannitol-induced rebleeding from intracranial aneurysm. $J$ Neurosurg 1983;59:529-30.

31 Ishimori S, Oshida K, Sankawa H. Hypervolemic hypotension in surgical treatment of intracranial aneurysm. Surg Neurol 1979;11:119-22.

32 Hamby WB. Intracranial surgery for aneurysms. Effet of hypotension upon survival. $J$ Neurosurg 1963;20:41-50.

33 Drake CG, Barr HWK, Coles JC, et al. The use of extracorporeal circulation and profound hypothermia in the treatment of ruptured intracranial aneurysms. $J$ Neurosurg 1964;21:575-81.

34 Silverberg GD, Reitz BA, Ream AK. Hypothermia and cardiac arrest in the treatment of giant aneurysms of the cerebral circulation and hemangioblastoma of the medulla. J Neurosurg 1981;55:337-46.

35 Cabral RJ, King TT, Scott DF. Epilepsy after two different neurosurgical approaches to the treatment of ruptured intracranial aneurysms. J Neurol Neurosurg Psychiatry 1976;39:1052-6.

36 Kosnik EJ, Hunt WE. Post-operative hypertension in the management of patients with intracranial arterial aneurysms. $J$ Neurosurg 1976;45:148-53.

37 Brown FD, Hanlon K, Mullan S. Treatment of aneurysmal hemiplegia with dopamine and mannitol. J Neurosurg 1978; 49:525-9.

38 Drake CG, Allcock JM. Post-operative angiography and the slipped clip. J Neurosurg 1973;39:683-9.

39 Suzuki J, Kwak R, Katakura I. Review of incompletely occluded surgically treated cerebral aneurysms. Surg Neurol 1980; 13:306-10. 